\title{
Tourism Marketing Consciousness: The New Posture of the Tourism Consumer Citizen
}

\author{
Celso José de Campos \\ Federal University of Rio de Janeiro (UNIRIO), Rio de Janeiro, Brazil
}

\begin{abstract}
We know that increased population and unrestrained consumption are generating problems, which becomes critical for our planet. This impending context is part of a whole system, triggered by a logic operation which needs to be reconsidered urgently. The consumer consciousness of tourism knows to what extent their different actions will help change something. To achieve this awareness of sustainable consumption requires a restructuring and reform of the cultural, social, and political aspects of the site and the citizen. With this vision and the proposal for a case study of tourism marketing consciousness, the objective of this study is to raise consumers' awareness of tourist destinations to develop their abilities to use the right information to make the right choices and to be ecologically responsible. Through this differential, every action carried out in the tourist spot is of singular importance to create sustainable added value for the citizen. In this case, tour operators, non-governmental organizations (NGOs), and local governments should also invest in educational programs that guide these consumers to enjoy as citizens the tourist areas consciously and effectively. Thus, we believe that training in tourism will lead the stakeholders of consciousness tourist destination to feel protagonist in the broad economic context, social, political, and cultural society of the destination of their choices.
\end{abstract}

Keywords: tourist, marketing, consciousness, consumer, sustainability

\section{Human Beings Destined to Transformations}

As the market is currently very competitive, it is no longer the producer who dictates the rules of the market, but rather the consumer. Behaving in a complex way and knowing their rights, we believe that it is time for consumers to become the protagonists of a society increasingly demanding consumers, an environment that is characterized by rapid and unpredictable changes.

With more purchase options, the consumer gained force-something that, previously, was featured by its passivity in the face of offers from suppliers - to become an agent who, in many cases, can define the future of a company. The suppliers who maintained their previous posture, that is, they believed that they could "push" their products on consumers, are experiencing great difficulties.

With the Real (Brazilian currency) plan, conceived in July 1994, consumers now have a better idea of the value of their money to better plan their purchases. Unlike in previous years, when consumers, particularly the poor, have to run to the supermarket the day they received their salaries but could not buy the same amount the next day, consumers nowadays can better control their consumption and evaluate more effectively the quality of their consumption.

Celso José de Campos, D.Sc., adjunct professor, School of Industrial Engineering, Federal University of Rio de Janeiro (UNIRIO).Email: celso.campos@uniriotec.br. 
As the increased population and unrestrained consumption are generating problems, to the extent that threatens the viability of all species of life on earth, we find that this impending context is part of a whole system, triggered by a logic operation which needs to be rethought for an urgent and global change.

Consumers do not know to what extent their different actions will help change something, being a great need for information. It is necessary to have an environmental education program for the training of conscious consumers. This training of conscious consumers leads to a more clarified awareness, generates a critical sense, and broadens the vision for that new choices are established.

The goal of the process is to make consumers learn to choose with consciousness, providing them with the right information to make the right choices. We found that the conscientious consumption becomes, then, a much broader concept, which today is beyond economic dictates, consumer rights, or forest devastation.

It is not a reactive posture, but leads consumers to identify themselves as performers within that broad social, political, and cultural context. As the consumer has power, he/she must try to use it for the benefit of a more sustainable society, where part of the basic shape of the citizen consumer is to become a consumer citizen.

People also need to get a sense for their lives, not only for consumption. The meaning of life would be the emotions, affections, and friendships, the things that actually constitute the well-being of people, and consumption would be just a tool for wellness. This society, from an environmental point of view, would be much more sustainable. From an economic standpoint, the consumer would have much less risk if he/she consumed strictly necessary to add value to his/her experience. Thus, consumers, making that change in their life styles and personal values, would feel more in touch with others, and they can get the opportunity to devote to their spiritual development and seek to have a fuller life of personal achievements. For this, awareness of consumer citizen tourism becomes essential.

According to Maslow (1954), with the understanding that the motivation is what moves people, the driving force behind all human behaviors can be defined as the state of motion or excitement that drives the behavior in the direction of a target object. Thus, for the author, the motivation has two components: the motion (or excitation) and the target object. As the concepts of necessity and desire are very close to the concept of motivation, the need is defined by the author as a feeling of deprivation of the desired state.

The desired state provides the target object and deprivation, the motion. An important issue for the study of the attitude of the citizen conscious tourism refers to knowing how many needs are to be explored and fulfilled in the tourist destination. To overcome this problem of an almost infinite number of possible needs that a human being can feel, psychologists and researchers of consumer behavior suggest studies on various categories of needs. For the purpose of this work, we will stick, based on Maslow's hierarchy of needs, simply to the self-realization needs.

What separates us to satisfy our need for self-realization is the awareness to know that the collective interests seem to have fallen out of favor at the same time an atmosphere of distrust and discouragement settles as an inevitable reality without alternatives (Lasch, 1984). We live in a kind of lack of solid prospects, which leads people to despair and apathy. Immersed in their dens, where televisions, telephones, and computers offer means of interaction causing isolation and a form of wish fulfillment of alienating character, many people assume passive postures towards the world around them. A strange desire of not to be involved in anything, not to commit, and to leave things as they are makes social bonds devoid of ideals and solidarity pacts (Wolpert, 2003). 
For this, we need to notice the possibility of understanding the processes, not as a Cartesian logic, which would be expected ever since the beginning, middle, and end, or any other relationship that would involve nonlinearities, but the processes of deterritorialization of events and no more finite and localized stories. Deleuze (1962) pointed out that, in deterritorialization processes and consequent new territorializations, there would be continuous reconfiguration of the elements which, far from being able to account for a fixed and predictable structure, were always plugging and unplugging of new assemblages. For this, the author pointed out that the first step, if we want to know and position ourselves satisfactorily in the world we live, is to become aware of what is happening around us and then act on one of the chosen directions.

Let us now study the importance of marketing conscientious perception of the citizen consumer tourism, leading him/her to understand the degree to which different actions will help to change something. With this awareness of sustainable consumption, every action performed in the tourist destination is loaded with sustainable value, where the citizen can self-realize and the community of the destination can improve their quality of life.

\section{The Contribution of Marketing to the Formation of a Society of Conscious Consumption}

The globalization of service industries has been accelerating under pressure from technological advances in communications, transportation and travel, the comprehensive deregulation and increasing competition, as well as the biggest global product demand for global citizens. The explosion of the internet and globalization made possible the emergence of a new channel of interaction with society, with great potential for doing business. At the marketplace we live, then, there are moments of euphoria and expectation of large gains in this environment. This perception was reflected in the valuation of virtual enterprises, worth more than big corporations of the traditional economy. The losses listed in virtual companies, the stock market, National Association of Securities Dealers Automated Quotation (NASDAQ), and the consequent bankruptcy of several businesses in this environment brought about a change in the behavior of the market.

If there were intelligence and sensitivity, even worse situations than what we see today in terms of social misery, violence, economic crisis, and popular revolt could be avoided. Anyway, the course of civilization is decided in an increasingly fast and global manner. It is clear the interdependence of all beings and the common destiny that unites the rich and the poor, businessmen and workers, powerful and humble, followers of any religion or to none of them. This scenario dramatically affects the performance of marketing in organizations.

After the agricultural and industrial revolutions, which quickly allowed increased production efficiency and the development of transport, communications, and a vigorous consumption market, in year 2000, according to many economic studies, it is pointing to a revolution, a discontinuity, and a sudden jump in the history of economics and marketing.

In many cases, it will be possible to say that it will not be as necessary as process efficiency, provided that it has agility and speed in customer services as if it was the only one. The market will also require a different way for the treatment of consumers. It is not enough to treat it as the focus to be achieved; it will also be necessary to maintain and nourish the consumers as partners or co-producers.

Wilkie and Moore (2003) stated that marketing is among the most complex, challenging, and intellectually stimulating academic areas because of its contributions from various disciplines, such as economics, psychology, history, mathematics, sociology, law, political science, communication, anthropology, and the 
creative arts. It combines objectivity and subjectivity, quantitative and qualitative views, freedom of imagination, and concrete actions. They stressed, however, that the formal marketing thinking has advanced a lot since its emergence mainly by accumulating more knowledge as time passes by, spreads by society, and occurs within the context of our daily lives.

At the turn of this century, the aggregate system of marketing, along with other aggregated systems with which the marketing interacts (technology, finance, and production), was responsible for providing many changes to society, namely, economic growth, higher income, and technological innovations of products and services. Thus, a wide range of these results have become tangible to the whole population.

As time passes by, the contributions made to society by the aggregate system of marketing are highly visible.

Then, we raised our question: Why do all companies not become equally rich and successful?

We know that many factors contribute to the success and failure of the policy of deploying an aggregate system of marketing in its proposal to provide contributions to society. We also know that everything will depend on the moral values that drive the culture of the consumer society in question, where the differences lie in the performance of public and private institutions. With that, still based on Wilkie and Moore (2003), we can infer that the criticisms and problems on performance of the aggregated marketing system, as leverage for the development of a society in general, can be focused on the following issues, summarized as follows:

(1) A "consumer culture": encouraging the materialistic consumption without measuring the social consequences, cultural imperialism, unlimited unsustainable consumerism, inequality in the distribution of benefits, emphasis on private and public deterioration, waste, morality, etc.;

(2) Consumer rights: serve the interests of the consumer and the producer, government guarantees, health, safety, quality, information, human rights, and ethics of propaganda;

(3) Marketing practices: privacy of information, preservation of natural resources, threats to the environment, disposal, recycling, approval processes, trade barriers, antitrust legislation, consumer dissatisfaction, business ethics, self-regulation, and social responsibility.

It is necessary, then, due to the magnitude and complexity of the global economic environment, that the government policies, marketing professionals, institutions, and academia examine some "hidden" aspects of processes, namely:

(1) The loss of cohesion of society by globalization;

(2) The challenges to ethical systems and religious beliefs;

(3) Customs barriers;

(4) Antitrust policies;

(5) The risks;

(6) The advantages of unlimited internet penetration;

(7) The invasion of privacy;

(8) The need for marketers to implement sales strategies with the social responsibility to serve the public interest and preserve these resources;

(9) The need for more academic studies to aim at developing theories and measurements of the value of various marketing actions in society, etc.. 


\section{The Meaning and the Importance of Marketing Consciousness: A Science With a Conscience}

Botton (1997) stated that human nature is seen as essentially selfish and self-centered, and it appears that if we act properly, we do so by virtue of our education and socialization, as we were taught to repress our naturally greedy and aggressive instincts.

Without constrictions and positive incentives, there might just be the "barbarism". The author also declared that this selfish version of human nature found enough support among philosophers, and its most poignant formulation appears in the 17th century, the Leviathan (L651) by Thomas Hobbes. The life of men in the state of nature without laws or government, for Hobbes (1651), was solitary, poor, nasty, brutish, and short, since men, by nature, are aggressive, self-centered, greedy, and are obsessed with a desire for immediate gains.

Darwin (1859) has already explained that only genetic traits to the reproductive success of individuals had a chance to settle in kind; similarly, character traits that lead to personal gain would be eradicated over time. For Darwinian hard-liners, there would be no evolutionary reason to act otherwise, just as it would be sheer madness to dive into a river to save a child.

Buzzi (1991) inserted in his studies of consumer behavior the conscious use of resources. According to him, consciousness means being close to... with some knowledge with science. Consciousness signals the most characteristic movement of our being: We are opening. He also stressed that we are not closed in on ourselves, because we are a factual possibility of linkage, communication, and because we live in a space of its own knowledge: Everyone has his/her own conscience. We use the word "consciousness", continued the author, to indicate the set of psychic functions that manage "big business" of our lives. In fact, when we choose to do something, when we decide to do it, and when we stop to analyze the way of doing it, we consult consciousness as if it were oracle and manual that provide the instructions on that choice. As Buzzi (1991) explained to us, Plato, a Greek thinker, had defined consciousness as "a dialogue" of the soul with itself, with an increased understanding that transcends the aspect of living. Dialogue consciousness primarily attests its destination reference and openness. It opens to the world, and it embodies, rejoices, and grieves in its own way of being embodied in the world.

Segal (1999) stated that man is naturally imposed a limit to acquire more and more things. A different manifestation of this is that it is avarice or an expressed desire to possess more than necessary, it is a form of mental and emotional blockage that prevents lives in depth. The author also clarified that the function of the material economy is to meet the basic needs of the individuals so that they can think and work around other higher goals of life.

The values of the patterns are changing. As the dominant paradigm asserts that a good life is obtained with the satisfaction of desires, especially desires that can be met through material consumption. The author offered us a proposal to live with simplicity in that the economic contribution to people's happiness is to offer the goods to the services they want. The opposing view, he pointed out, where an economy does well, due to the constantly increasing production and consumption, is depleted. He revealed that:

The forms of production must be socially just and ecologically smart. All people should have access to an economic security. The production must not aim only to get money, but should be, in fact, useful to the community. From the perspective of the paradigm of simple life, producing weapons of war, for example, is not justified. The efficiency of an economy nor is evaluated only for its growth. Need to know if it meets the needs of all basic materials and makes room for the free pursuit of happiness in walks of life that are not governed by the material economy. (p. 32) 
The author finalizes condemning the current economic paradigm that tends to put human life as the life of the natural environment in the service of money, for the sake of simplicity that the economic paradigm proposes that the money be put to the service of life, and this change of pattern should be promoted simultaneously in individual space and collective space.

To trace the middle way between the extremes of consumerism and poverty, we observed that for individuals to adopt the idea of simplicity, they need to retrain their habits so that they can have a richer inner life and be more prosperous in happiness. Thus, the individual's posture is changed by the relentless pursuit of material goods, which leads to reconnecting people, the natural rhythms of life, and their own noblest sentiments. In nature, the relations of buying and selling cease to be an obsession. Money does not buy into the habit of reading good books or the ability to love, to meditate, and to be happy listening to birdsongs.

We see, then, a strong tendency, i.e., the humanization of capitalism, where the financial resources are available to all, building a world in which we all win. With the rational use of resources, aiming at the humanization of capitalism, and with intelligence and sensitivity, even more serious situations than those we see today in terms of social misery, violence, economic crisis, and popular revolt can be avoided. Anyway, the course of civilization is decided in an increasingly fast and global manner.

Underhill (2009) claimed that consumers are tired of much advertising. The author stressed that more marketers and advertisers dictate the rules through numerous advertisements making consumers buy everything that was shown. As the consumerist society is living on borrowed time due to the major change of the profile of the sexes, the social and economic situations, one realizes that, according to the anthropologist, there is a trend that consumers are more aware of their choices, get what is needed for their lives, and avoid unnecessary consumption.

Underhill (2010), featuring some of its analyses, discovered the new profile of women and men in consumption. The woman, according to the author, finds herself in a new social reality, she works and therefore stands, showing impatience on purchases and retention at the expense. On the other hand, the supermarkets seek to adapt to this new profile, changing the layout of the products to make faster purchases.

Men, who are impatient in purchases, as the author defined, are more interested in appearance. They go to supermarket to cultivate hobbies at home, how to cook, etc..

The term consciousness comes from the contribution of the mastermind of the "concept of conscious consumer”, Helio Mattar, co-founder of the Akatu Institutewhich, who, since 2001, defined it as an exercise in solidarity and otherness, in the sense that this is the act of doing something considering others and working for the benefit of others. He further stated that consumption as the "act of solidarity" means that if we are aware of the miracle that perhaps we failed to subordinate so strongly our happiness to material, fleeting, and perishable goods, which alienate us from the beauty of people and the world and of all that is permanent and essential, putting us in an endless competition for increasingly intense consumptions, as if, with this, we could create for ourselves an identity that would make us different from our peers. The author continued emphasizing that:

This competition poses a risk to all humans, without exception. In the current situation, where 1.7 billion of the 6.6 billion inhabitants of the world consume much more than necessary, while others consume or the minimum necessary or below this minimum, the use of natural resources_-breathable air, clean water, farmlands, and absorption of the wastes produced by humanity - is already at a level $25 \%$ higher than the Earth can renew. And if everyone in the world were to consume as the richest people on the planet, we would need four Earths to supply all this consumption, a model of production and consumption, therefore infeasible to be expanded to all mankind. (Mattar, 2006, p. 5) 
In this sense, we have reinforced the idea that we have to raise our children, since the fundamental course, providing a supportive consumer education. With this procedure, we can reverse the perverse logic of competition by consumption and guide these students to consume with consciousness towards others and not just themselves.

This meaning is reinforced by the president of the Institute for the Development of Social Investment, Marcos Kisil, who stressed, however, that the Brazilian consumers, nowadays, are more aware not only of their rights, but also of the roles that citizens and businesses should play in society, as proactive agents of development.

However, this optimism is relativized when we analyze some studies on the subject. The Akatu Institute released, in year 2010, a study on how and why the Brazilians practice conscious consumption. The results of the survey showed that, in addition to the decrease of the number of consumers considered engaged, there is still a divergence between what is proposed as a principle and what is really practiced.

Mattar has already said that the concept of conscious consumption is still in transition and thus tends to susceptibility of behaviors and opinions of immediate context. This suspicion is reinforced by the survey conducted between September and October 2006, by IBOPE Intelligence (a respected research institute in Brazil), where 537,381 executives of major Brazilian companies were interviewed to figure out how they see the concept of sustainability and its implications on the everyday lives of these organizations. Through the answers, the researchers of the institute were able to detect paradoxes between what is meant by sustainable and what is actually done to reach this purpose, especially when it translates into strategic issues.

When the awareness of sustainable consumption prevails in public institutions, private institutions, as well as in the institutions of the third sector, their strategies are more ambitious, it must be presenting results above a strategic plan that will benefit society as a whole.

\section{Case Study: The Carioca Slum as a Tourist Destination of Conscious Citizens}

This case study is presented to investigate whether the success of the viability of the favelas of Rio de Janeiro as tourist destinations is due to the concept of sustainable consumption, assimilated by the agents of the promoters of this event. With this, we can infer that the deployment of marketing consciousness is necessary as an effective instrument for intervention in the process of formation of a Rio de Janeiro slum as a tourist destination, adding immense value to the local community. For the development of our work, we resort to a case study by Professor Bianca Freire-Medeiros with his research, where he produced an article named, The Construction of the Carioca Slum as a Tourist Destination, and made a critical analysis of how the marketing concept of consciousness was applied to the actions of adding value, aiming to make the slums of Rio de Janeiro self-sustaining and viable tourist destinations. In this analysis, the aim was also to investigate the responsibilities of promoters of tourism, non-governmental organizations (NGOs), community leaders, and public entities in the promoters of satisfaction of needs and prevailing desires of community members and stakeholders that shape the tourism product process as such.

According to the author, travel to sites associated with suffering is not a new phenomenon and refers to the first religious pilgrimage, in this case, the so-called "reality tours" in Rio's favelas which, here, was characterized as the "real passion" by Badiou (2002). It is simply the possibility of development of poor communities in the city of Rio de Janeiro, which still remains intact, called "authentic culture", free from the corrosive influences of the external environment, as a key element in the composition of the so-called "alternative" tourism product. 
Tourism agencies that promote visits to Rio's favelas almost exclusively employ professional guides, which would aim to train the youth of the slum to be helpful guides. The initiative provokes uproar among tourism operators: Some of them see it as an employment opportunity for local youngsters, while others criticize it as a purely demagogic and patronizing thing to the extent that young people would not be prepared to act outside the favela. Another controversy is that the author is the ethical dimension of tourism operators, who believe that their business has an important "social dimension" in that it "boosts self-esteem of the slum that gets people around the world wanting to know them". Visits to nurseries during which tourists are encouraged to make donations are also common practices for all agencies as well as the rental of slabs that act as lookouts. One of the agencies is responsible for providing a means of income for the population of the slum.

The encouragement of local artists, whose arts are presented to tourists for purchase of a memory location, is also part of the work of the travel agencies. The author showed that in one of the slums, a cooperative was organized, named "Coop Babilônia", which organizes the tours of the slum and controls the activities of travel agencies, in order to regulate and fulfill the needs and desires of the community. This cooperative believes that tourism should be seen as an opportunity for sustainable development. Thus, any profit generated reverts to the locale and its ecological park. On the other hand, there are investments to transform the ride experience just visual or even voyeuristic, something uplifting, encouraging the interaction between visitors and residents, learning about local history and an "environmentally friendly" encounter with the nature. In this way, tourism not only works with the generation of income, but it is also a major work of generation of self-esteem for residents, because seeing the community being visited starts to give greater value to the community itself.

The government of the city of Rio de Janeiro, explains the author, also manifests as a promoter of development of tourist destination, ushering in one of the oldest slums of the city's "Open Air Museum”.

In this context, this government opened a cybercafe and recovered several "historical sites" which are of vital importance in the history of the city. With these increases in tourist destinations, the flow of tourists became larger and steady, coming through icons of tourism in the city of Rio de Janeiro with the sugar loaf and Corcovado, according to data collected in the local press. With this, the residents realize that their habitat becomes a valued and potentially lucrative place, since they produce handicrafts and shirts offered for sale at the Association of Residents. In this process, the author claimed that the city also undertook to provide training to interested residents, but even before the formal training, many are already accompanying the tourists, telling stories of slums, and showing the points they deem of interest to the visitors. Even "Michael Jackson", who, in 1996, in his stay in Brazil to shoot scenes for his single named They Don't Care About Us, directed by Spike Lee, chose a slum in southern Rio as the setting to carry out a video which had as its subjects the life of the poor in major cities of the world and official indifference to their pleas. The local population was so touched and appreciated that they wanted to build the Michael Jackson Museum as one of the tourist attractions of the favela. It was found that, with the analyses described in this case study, all actions motivated for a restructuring and reform of the cultural, social, and political aspects, in order to achieve awareness of sustainable consumption, lead to the potentiation of the tourist destinations. With this vision and the contribution of the study of tourism marketing consciousness, the consumer citizen, tourism operators, the consumer citizen of tourist destinations, and the city hall are sensitive to sustainability projects of slums in Rio as tourist destinations, namely: 
(1) Through the travel agencies: visits to slums in Rio-employing almost exclusively local professional guides; reception of tourists in the world to introduce them to the site seeking increased self-esteem of slum dwellers; visits to the charitable works of the slum where tourists are encouraged to make donations; rent of "lages" (social spaces) that act as lookouts; and encouragement of local artists, whose arts are presented to tourists for purchase of a memory location;

(2) Through NGOs: promotion of local associations for the citizenship rights of slum dwellers; creation of events that bring dignity to the residents, such as health, education, arts, etc.;

(3) Through the city of Rio de Janeiro: opening of cultural centers, promoting events of interest, creating training courses for labor tourism location, opening of museums, arts, panoramic lifts, etc..

\section{Concluding Remarks}

We found that the deployment of marketing conscientiousness causes the consumer citizen to understand the degree to which different actions will help change something. With this awareness of sustainable consumption, it becomes sensible to develop tourists' ability to use the right information to make the right choices and be environmentally responsible. So with that mindset, every action performed in the tourist spot is of singular importance to come loaded with sustainable added value for citizens and community, where the tourist destination is established. Local governments, on the other hand, feel encouraged to invest in educational programs that guide these consumers to enjoy as citizens the tourist areas consciously and effectively. We illustrate this approach with a case study, where the conscious citizens feel that they are protagonists in the broad economic, social, political, and cultural context of the tourist destination in the slums of the city of Rio de Janeiro, through the so-called reality tours. Recognized as viable tourist destinations, slums, both by the public administration which came to promote tourism in these towns by local, could be promoted, sold, and consumed in different ways: as a physical and/or social landscape, as an ecotourism destination, and as adventure and/or cultural tourism. Thus, the citizen conscious tourism sees opportunity in this space of satisfying their clear needs for self-realization.

We also note that the so-called "contact zones" in the slums in Rio are "social spaces" where different cultures meet, intertwine, and collide with one another, often asymmetrical. Thinking the slum through the deployment of marketing conscientiousness means exploring the existing tourism as contact zones in a physical and symbolic territory in which discursive layers settle in multiple representations: representations about the slums and their inhabitants formulated by tourists, tourists' representations expressed by residents, and the representations made by slum residents for tourists in a continuous spiral of representations in a sustainable way. Limitations of this study were due to make a choice: with the political visibility of Rio slum study, both projects could attract for good or for evil. With the choice going right, we can cite the NGOs' agencies, tour operators, the City Hall, and the consumer citizen of authenticity as promoters of the event. If it was worse, this potentiation of tourism could be exploited by the authority of the local drug trade, if emanating, then, relations of domination and subordination, which paradoxically emerge other possibilities of representation of the self and the other.

Finally, it is expected that the researchers expand this knowledge both for the slums and for other authentic places so that their viability as a sustainable tourist destination can be ensured. 


\section{References}

Badiou, A. (2002). Pequeno Manual de Inestética. In B. Freire-Medeiros (Ed.), A construção da favela carioca como destino turístico. Rio de Janeiro: CPDOC.

Botton, A. (1997). Mistérios do bom e do mau (p. 5). São Paulo: Folha de São Paulo, Caderno MAIS.

Buzzi, A. R. (1991). Filosofia para Principiantes: A existência humana no mundo. Petrópolis: Vozes.

Darwin, C. (1859). A origem das Espécies. Retrieved from http://ecologia.ib.usp.br/ffa/arquivos/abril/darwin1.pdf

Deleuze, G. (1962). Nietzsche et la Philosophie. Paris: PUF.

Hobbes, T. (1651). LEVIATÃ ou a matéria, forma e poder de um estadoeclesiástico e civil. São Paulo: Coleção Fundamentos do Direito.

Lasch, C. (1984). O minimo eu: A sobrevivencia psiquica em tempos dificeis. Sao Paulo: Brasiliense.

Maslow, A. H. (1954). Motivation and personality. New York, NY: Harper \& Row.

Mattar, H. (2006). Consuma sem consumir o mundo em que você vive. Revista Ibero-Americana de Estratégia, 5(2), 5.

Segal, J. M. (1999). Graceful simplicity: Toward a philosophy and politics of simple living. New York, NY: Henry Holt.

Underhill, P. (2009). Vamos às compras: A ciência do consumo nos mercados globais. São Paulo: Campus.

Underhill, P. (2010). O que as mulheres querem: Descubra porque o mercado global se rendeu ao poder feminino. São Paulo: Campus.

Wilkie, W. L., \& Moore, E. S. (2003). Scholarly research in marketing: Exploring the “4 eras” of thought development. Journal of Public Policy and Marketing, 22(2), 116-146.

Wolpert, L. (2003). Tristeza Maligna: A Anatomia da Depressão. São Paulo: Martins Fontes. 